\title{
End-diastolic amplitude of mitral valve echogram in mitral stenosis
}

\author{
PAVLOS TOUTOUZAS, ANASTASIOS VELIMEZIS, ELIAS KARAYANNIS, \\ AND DEMETRIS AVGOUSTAKIS
}

From the Department of Cardiology, Medical School of the University of Athens, Hippokration Hospital, Athens, Greece

By using simultaneous recordings of the mitral valve echogram and apex cardiogram, the mitral echogram amplitude was measured at the onset of left ventricular isovolumic contraction (MAIC). Twenty normal subjects and 68 patients with a reduced diastolic closure rate in the mitral valve echogram were studied. Of these patients, 53 had mitral stenosis, 6 aortic valvar stenosis, and 9 hypertrophic obstructive cardiomyopathy.

In the normal subjects the MAIC ranged between 2 and $4 \mathrm{~mm}$, average $2.7 \mathrm{~mm}$, in the patients with aortic valvar stenosis or hypertrophic obstructive cardiomyopathy between 2 and $4 \mathrm{~mm}$, average $2.9 \mathrm{~mm}$, and in the patients with mitral stenosis between 6 and $17 \mathrm{~mm}$, average $11.3 \mathrm{~mm}$.

The DE/MAIC ratio, where DE represents the opening amplitude of the mitral valve in early diastole, was between $3 \cdot 3$ and $6 \cdot 5$, average $5 \cdot 1$, in normal subjects; in the patients with aortic stenosis or hypertrophic obstructive cardiomyopathy the $D E / M A I C$ ratio was between 2.7 and 6.5 , average 4.2 , and in the patients with mitral stenosis between 0.7 and 1.5 , average $1 \cdot 1$. An excellent correlation was found between the $D E /$ $M A I C$ ratio and mitral valve area in the patients with mitral stenosis $(r=0 \cdot 84, P<0.01)$ while the correlation between the diastolic closure rate and valve area was less satisfactory $(r=0.62, P<0.01)$. These findings suggest that in cases with a reduced diastolic closure rate for reasons other than mitral stenosis, error can be avoided by using the $D E / M A I C$ ratio.

The diminished diastolic closure rate of the anterior mitral valve leaflet on the echogram has been accepted as a reliable sign for the diagnosis of mitral stenosis. However, the same abnormality may be seen in patients who show a decreased rate of left ventricular filling for reasons other than mitral stenosis. Such patients may suffer from obstructive cardiomyopathy, severe aortic valvar stenosis, or other diseases (Shah et al., 1969; Feigenbaum and Chang, 1972). Duchak et al. (1972) attempted to differentiate these cases by the study of the posterior mitral valve leaflet; their conclusion, on which there is no general agreement (Levisman et al., 1975; Ticzon et al., 1975), was that mitral stenosis is associated with an abnormal anterior motion of the posterior leaflet whereas non-mitral diseases show a normal motion.

Studies have shown that in cases with increased left ventricular diastolic pressure, mitral valve closure begins earlier and is delayed (Pridie et al., 1971; Feigenbaum and Chang, 1972). On the other Received for publication 3 June 1976 hand, in mitral stenosis the valve remains widely open at the end of diastole, and there is evidence that it closes rapidly during pre-isovolumic contraction of the left ventricle (Pridie et al., 1971; Fortuin and Craige, 1973; Toutouzas et al., 1974).

The present study investigates mitral valve closure in mitral stenosis and other diseases in which there may be a reduced diastolic slope on the mitral valve echogram. We measured the amplitude of the mitral echogram at end-diastole, as an index of the severity of mitral stenosis and of its presence or absence in doubtful cases.

\section{Subjects and methods}

Studies were made in 53 patients with mitral stenosis, 9 patients with hypertrophic obstructive cardiomyopathy, 6 patients with aortic valvar stenosis, and 20 normal subjects.

The patients with mitral stenosis were 8 men and 45 women, aged 17 to 64 years, average 41 years. Mitral stenosis was confirmed by cardiac cathe- 
terisation and angiocardiography; in 9 patients it was combined with insignificant mitral regurgitation; none of the patients had aortic or tricuspid valve disease. The mitral valve area estimated by cardiac catheterisation was between 0.40 and $1.50 \mathrm{~cm}^{2}$, average $0.87 \mathrm{~cm}^{2}$. The mitral valve echogram showed a slow diastolic closure rate from $E$ to $F$, between 7 and $35 \mathrm{~mm} / \mathrm{s}$, average $17 \mathrm{~mm} / \mathrm{s}$. Twenty-four patients were in sinus rhythm and the remaining 29 were in atrial fibrillation.

The patients with hypertrophic obstructive cardiomyopathy or aortic stenosis (12 men, 3 women, 20 to 73 years of age) were included in the study if the following criteria were fulfilled: (a) confirmation of the diagnosis by haemodynamic studies and angiocardiography; (b) absence of a diastolic pressure gradient between the left atrium and left ventricle; (c) demonstration of a slow diastolic closure rate of the anterior mitral valve leaflet on the echogram, ranging from 19 to $40 \mathrm{~mm} / \mathrm{s}$, average $28 \mathrm{~mm} / \mathrm{s}$. An anterior midsystolic motion of the anterior leaflet was shown in 7 patients with obstructive cardiomyopathy. All these patients were in sinus rhythm.

Finally, the group of normal subjects consisted of 9 men and 11 women, whose ages ranged from 15 to 50 years, average 29 years. The diastolic closure rate was from 85 to $153 \mathrm{~mm} / \mathrm{s}$, average $109 \mathrm{~mm} / \mathrm{s}$.

Echograms of the mitral valve were obtained using a Hewlett Packard ultrasound device. Phonocardiograms and apex cardiograms were obtained using an Electronics for Medicine multichannel recorder and transducer (PSA-23). The gated mitral valve echo signal and lead II of the electrocardiogram were recorded simultaneously with the phonocardiogram and apex cardiogram. The recordings were made at a paper speed of $100 \mathrm{~mm} / \mathrm{s}$.

From each recording the following measurements were made:

(1) The mitral echogram amplitude in $\mathrm{mm}$ at the onset of isovolumic left ventricular contraction (MAIC) This was done by determining the position of the anterior mitral leaflet when the $C$ point of the apex cardiogram (onset of isovolumic contraction) was recorded, and measuring the perpendicular distance between that position of the valve and the $C$ point on the echogram, corresponding to complete valve closure (Fig. 1) (Zaky et al., 1968). In practice this measurement can be also made with reference to the electrocardiograms as the $C$ point of the apex cardiogram and the $R$ wave of the electrocardiogram are almost simultaneous (Wil'ems et al., 1971; Pridie et al., 1971).
(2) The mitral echogram amplitude in $\mathrm{mm}$ in early diastole $(D E)$, that is the perpendicular distance between the echographic points $\mathrm{D}$ and $\mathrm{E}$ (Zaky et al., 1968).

(3) The $D E / M A I C$ ratio In atrial fibrillation an average value was taken from measurements made in at least 5 consecutive cardiac cycles.

\section{Results}

Tables 1,2 , and 3 summarise the findings. NORMAL SUBJECTS (20)

The values of $\mathrm{DE}$, that is the mitral echogram amplitude in early diastole, ranged between 10 and $20 \mathrm{~mm}$, average $13.7 \mathrm{~mm}$.

The values of MAIC, that is the mitral echogram amplitude at the onset of the left ventricular isovolumic contraction, ranged between 2 and $4 \mathrm{~mm}$, average $2.7 \mathrm{~mm}$.

The DE/MAIC ratio ranged between 3.3 and 6.5, average $5 \cdot 1$ (Fig. 1).

\section{MITRAL STENOSIS (53 PATIENTS)}

The values of $\mathrm{DE}$ ranged between 5 and $18 \mathrm{~mm}$, average $12 \cdot 1 \mathrm{~mm}$.

The values of MAIC ranged between 6 and $17 \mathrm{~mm}$, average $11.3 \mathrm{~mm}$; the highest values were noted in patients with severe mitral stenosis.

The DE/MAIC ratio ranged between 0.71 and 1.55, average 1.07 (Fig. 2, 3, and 6). A good correlation was found between this ratio and the mitral valve area $(r=0.84, P<0.01)$.

Table 1 Results in 20 normal subjects

\begin{tabular}{|c|c|c|c|c|c|c|c|}
\hline $\begin{array}{l}\text { Case } \\
\text { No. }\end{array}$ & Sex & $\begin{array}{l}\text { Age } \\
(y)\end{array}$ & $\begin{array}{l}H R \\
\text { (beats/min) }\end{array}$ & $\begin{array}{l}D C R \\
(\mathrm{~mm} / \mathrm{s})\end{array}$ & $\begin{array}{l}D E \\
(\mathrm{~mm})\end{array}$ & $\begin{array}{c}M A I C \\
(\mathrm{~mm})\end{array}$ & $D E / M A I C$ \\
\hline $\begin{array}{c}1 \\
2 \\
3 \\
4 \\
5 \\
6 \\
7 \\
8 \\
9 \\
10 \\
11 \\
12 \\
13 \\
14 \\
15 \\
16 \\
17 \\
18 \\
19 \\
20 \\
\text { Avera }\end{array}$ & $\begin{array}{l}M \\
F \\
F \\
M \\
M \\
F \\
M \\
F \\
M \\
F \\
M \\
F \\
F \\
F \\
F \\
M \\
M \\
F \\
M \\
F \\
g e\end{array}$ & $\begin{array}{l}46 \\
16 \\
42 \\
50 \\
43 \\
40 \\
15 \\
30 \\
16 \\
24 \\
20 \\
20 \\
20 \\
24 \\
35 \\
19 \\
22 \\
50 \\
17 \\
36 \\
29\end{array}$ & $\begin{array}{r}65 \\
96 \\
92 \\
90 \\
90 \\
80 \\
78 \\
88 \\
83 \\
82 \\
76 \\
94 \\
96 \\
88 \\
84 \\
86 \\
100 \\
65 \\
60 \\
82 \\
84\end{array}$ & $\begin{array}{r}100 \\
110 \\
85 \\
102 \\
142 \\
130 \\
95 \\
142 \\
153 \\
105 \\
98 \\
90 \\
103 \\
120 \\
118 \\
105 \\
110 \\
80 \\
90 \\
104 \\
109\end{array}$ & $\begin{array}{l}13 \\
12 \\
14 \\
18 \\
16 \\
13 \\
12 \\
10 \\
15 \\
20 \\
11 \\
14 \\
10 \\
13 \\
14 \\
16 \\
13 \\
17 \\
11 \\
13 \\
13 \cdot 7\end{array}$ & $\begin{array}{l}2 \\
2 \\
3 \\
3 \\
3 \\
3 \\
2 \\
3 \\
3 \\
3 \\
3 \\
4 \\
2 \\
4 \\
4 \\
2 \\
2 \\
3 \\
4 \\
4 \\
2 \\
3 \\
2 \\
2 \\
2 \\
2\end{array}$ & $\begin{array}{l}6 \cdot 5 \\
6 \\
4 \cdot 7 \\
6 \\
5 \cdot 3 \\
6 \cdot 5 \\
4 \\
3 \cdot 3 \\
5 \\
5 \\
5 \cdot 5 \\
3 \cdot 5 \\
5 \\
6 \cdot 5 \\
4 \cdot 7 \\
4 \\
6 \cdot 5 \\
5 \cdot 7 \\
5 \cdot 5 \\
6 \cdot 5 \\
5 \cdot 1\end{array}$ \\
\hline
\end{tabular}

$\mathrm{HR}=$ heart rate; $\mathrm{DCR}=$ diastolic closure rate of the mitral valve echogram; $\mathrm{DE}=$ mitral echogram amplitude at onset of diastole; MAIC = mitral echogram amplitude at the onset of isovolumic left ventricular contraction. 
Table 2 Results in 53 patients with mitral stenosis

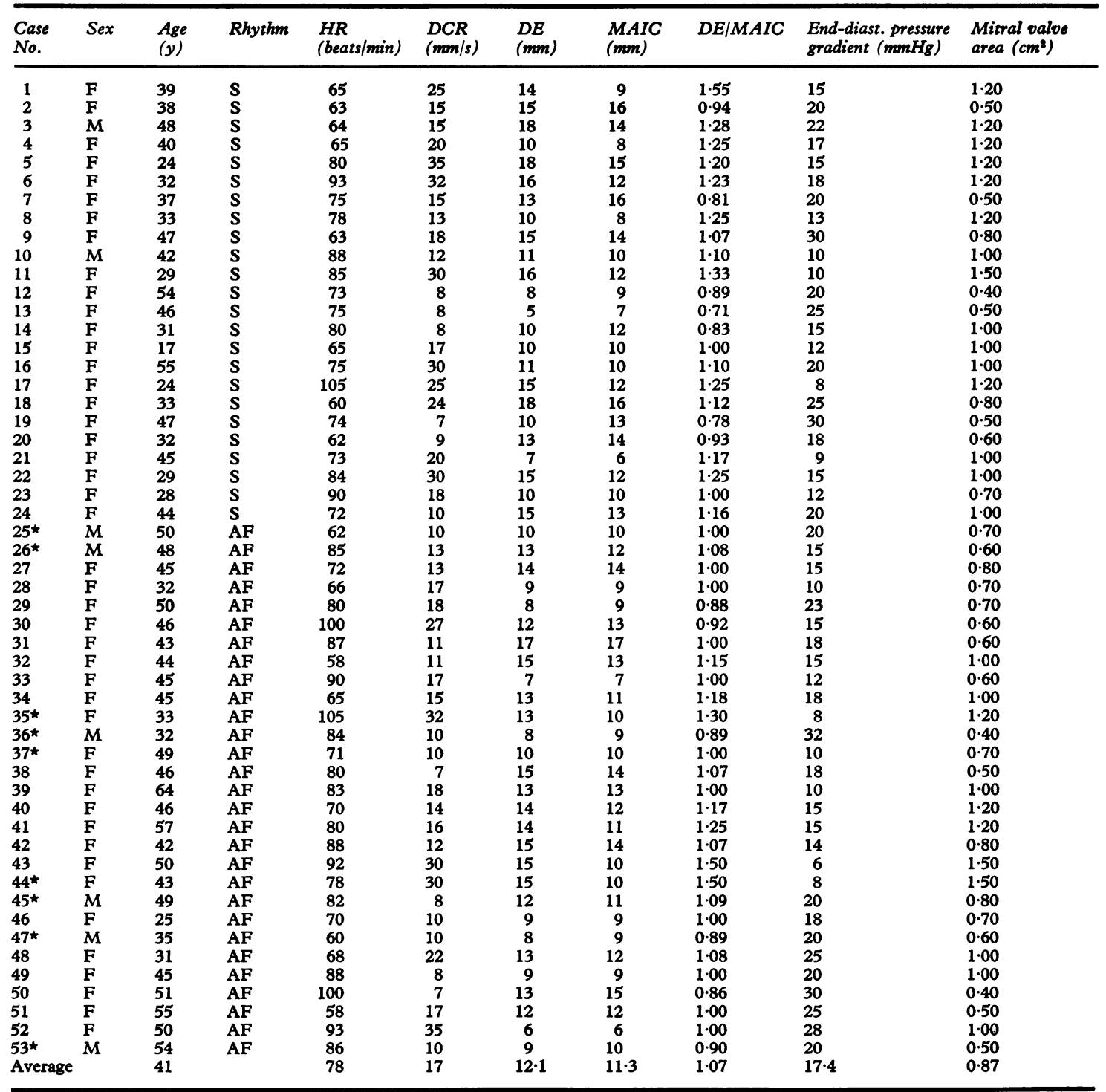

$\mathbf{S}=$ sinus rhythm; $\mathbf{A F}=$ atrial fibrillation.

^Patients with associated mild mitral regurgitation.

The correlation between the DE/MAIC ratio and the end-diastolic pressure gradient between the left atrium and left ventricle was poor $(r=0 \cdot 47$, $P<0.01)$.

HYPERTROPHIC OBSTRUCTIVE CARDIOMYOPATHY OR AORTIC VALVAR STENOSIS (15 PATIENTS) DE ranged between 8 and $17 \mathrm{~mm}$, average $12.3 \mathrm{~mm}$.
MAIC ranged between 2 and $4 \mathrm{~mm}$, average $2.9 \mathrm{~mm}$.

The DE/MAIC ratio ranged between 2.7 and $6 \cdot 5$, average $4 \cdot 2$ (Fig. 4 and 5 ).

\section{Discussion}

The present study showed that the amplitude of the mitral echogram at the onset of the left ventricular 
Table 3 Results in 9 patients with hypertrophic obstructive cardiomyopathy (HOCM) and 6 patients with aortic stenosis ( $A S$ )

\begin{tabular}{|c|c|c|c|c|c|c|c|c|}
\hline $\begin{array}{l}\text { Case } \\
\text { No. }\end{array}$ & Sex & $\begin{array}{l}\text { Age } \\
(y)\end{array}$ & Disease & $\begin{array}{l}\text { HR } \\
\text { (beats/ } \\
\text { min) }\end{array}$ & $\begin{array}{l}D C R \\
(\mathrm{~mm} / \mathrm{s})\end{array}$ & $\begin{array}{l}D E \\
(\mathrm{~mm})\end{array}$ & $\begin{array}{c}M A I C \\
(\mathrm{~mm})\end{array}$ & $\begin{array}{l}D E / \\
M A I C\end{array}$ \\
\hline 1 & $M$ & 27 & HOCM & 70 & 36 & 15 & 3 & 5 \\
\hline 2 & $M$ & 40 & HOCM & 72 & 40 & 14 & 3 & $4 \cdot 7$ \\
\hline 3 & $M$ & 35 & HOCM & 60 & 19 & 10 & 3 & $3 \cdot 3$ \\
\hline 4 & M & 27 & HOCM & 60 & 25 & 16 & 4 & 4 \\
\hline 5 & $\mathrm{M}$ & 51 & HOCM & 95 & 32 & 8 & 2 & 4 \\
\hline 6 & $\mathbf{M}$ & 58 & HOCM & 76 & 24 & 12 & 4 & 3 \\
\hline 7 & $\mathrm{~F}$ & 20 & HOCM & 100 & 22 & 12 & 3 & 4 \\
\hline 8 & $M$ & 38 & HOCM & 84 & 20 & 9 & 2 & $4 \cdot 5$ \\
\hline 9 & $M$ & 21 & HOCM & 65 & 20 & 11 & 4 & $2 \cdot 7$ \\
\hline 10 & $\mathrm{M}$ & 42 & AS & 64 & 34 & 16 & 4 & 4 \\
\hline 11 & $\mathrm{~F}$ & 42 & AS & 70 & 22 & 10 & 2 & 5 \\
\hline 12 & $\mathrm{M}$ & 73 & AS & 65 & 20 & 10 & 2 & 5 \\
\hline 13 & $M$ & 46 & AS & 62 & 38 & 12 & 2 & 6 \\
\hline 14 & $M$ & 61 & AS & 68 & 35 & 17 & 3 & $5 \cdot 7$ \\
\hline 15 & F & 44 & AS & 72 & 40 & 13 & 2 & 6.5 \\
\hline \multicolumn{2}{|c|}{ Average } & 45 & & 72 & 28 & $12 \cdot 3$ & 2.9 & $4 \cdot 2$ \\
\hline
\end{tabular}
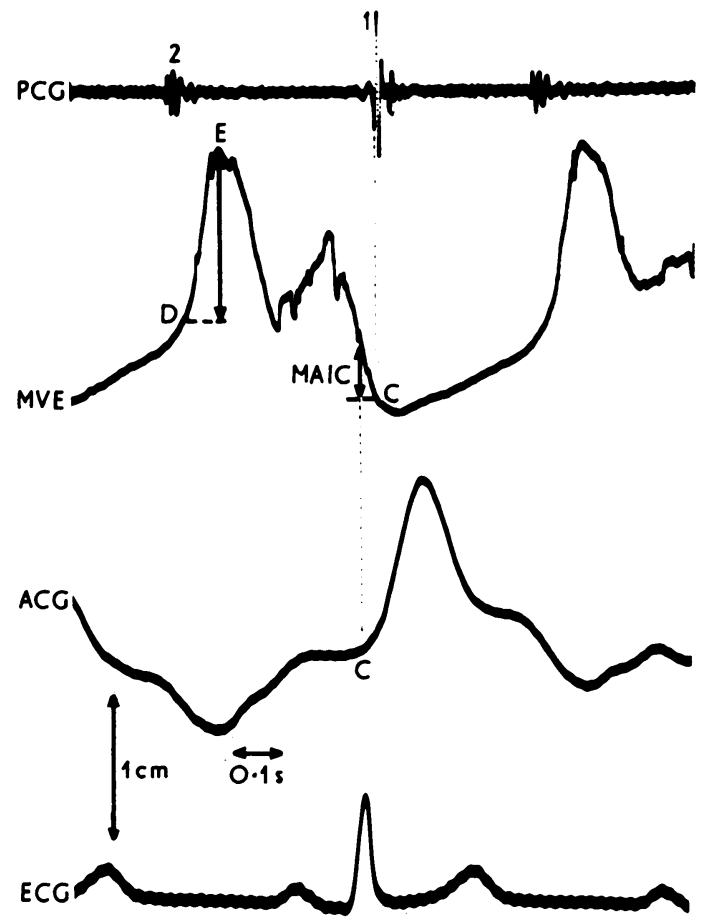

Fig. 1 Case 7 (Table 1). Normal mitral valve echogram with a diastolic closure rate of $95 \mathrm{~mm} / \mathrm{s}$. Mitral echogram amplitude at the beginning of diastole shown by the arrow $D E$ is $12 \mathrm{~mm}$. Mitral echogram amplitude at onset of left ventricular isovolumic contraction ( $C$ point of apex cardiogram or $R$ wave of electrocardiogram) shown by the arrow $M A I C$ is $3 \mathrm{~mm}$. $D E / M A I C$ ratio $=4$.

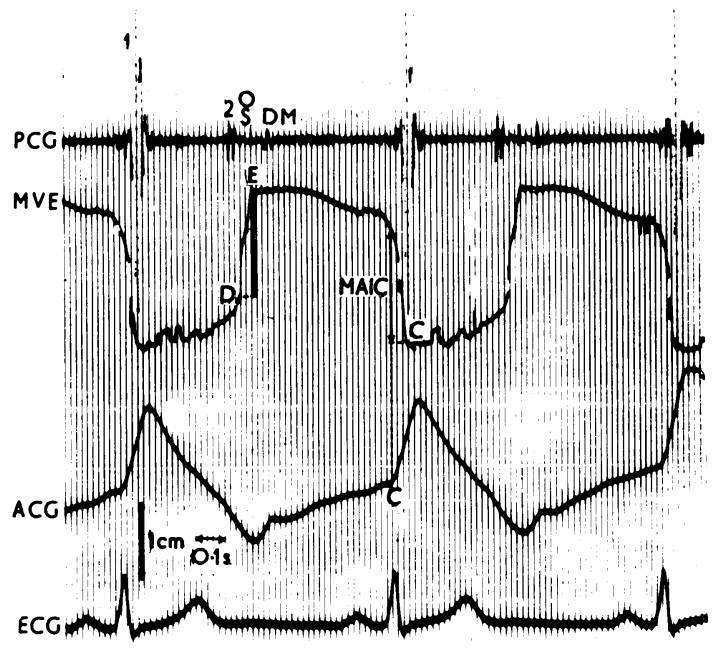

Fig. 2 Case 20 (Table 2). Mitral stenosis with sinus rhythm. Mitral valve is widely open at $C$ point of apex cardiogram (or $R$ wave) with increase of $M A I C$ $(14 \mathrm{~mm})$. Mitral echogram amplitude in early diastole, $D E=13 \mathrm{~mm} . D E / M A I C$ ratio $=0.92(O S=$ opening snap, $D M=$ diastolic murmur).

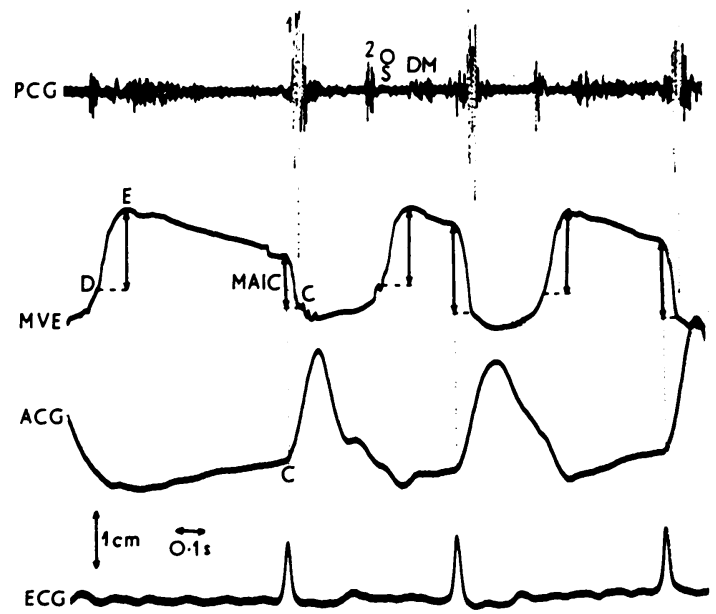

Fig. 3 Case 39 (Table 2). Mitral stenosis with atrial fibrillation. Cycle length affects mitral echogram amplitude at onset of isovolumic contraction. In first cardiac cycle with long diastole $M A I C$ is $9 \mathrm{~mm}$. In following two short cardiac cycles with increased mitral flow and pressure gradient at end-diastole, MAIC is increased (15 $\mathrm{mm}$ and $13 \mathrm{~mm}$ ). 


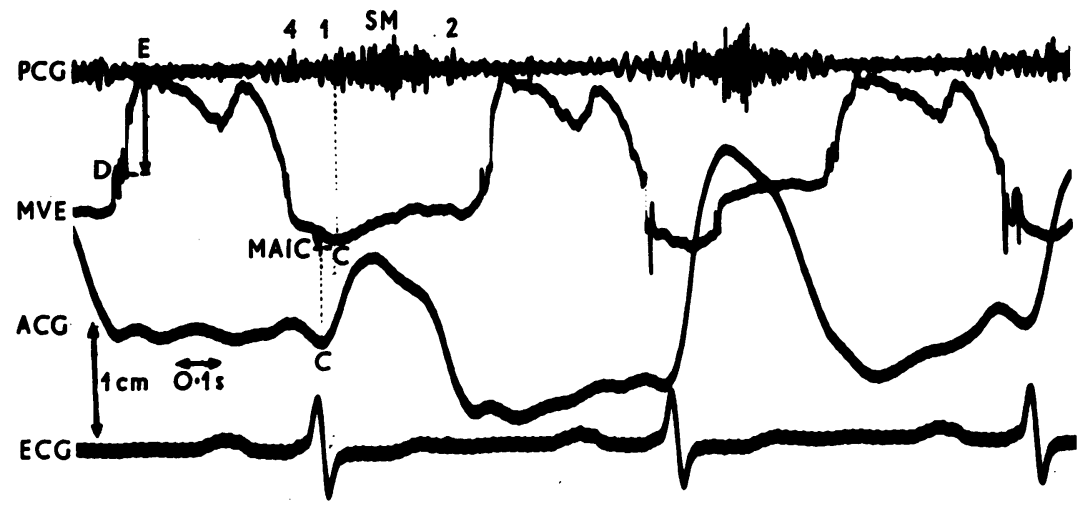

Fig. 4 Case 12 (Table 3). Calcific aortic stenosis. Cardiac catheterisation and angiocardiography showed normal mitral valve. Mitral valve echogram shows reduced diastolic closure rate $(20 \mathrm{~mm} / \mathrm{s})$, but at end-diastole anterior mitral leaflet is seen near to closed position well before $C$ point of apex cardiogram. $M A I C=2 \mathrm{~mm} . D E / M A I C$ ratio $=5$ (4=4th heart sound, $S M=$ systolic murmur).

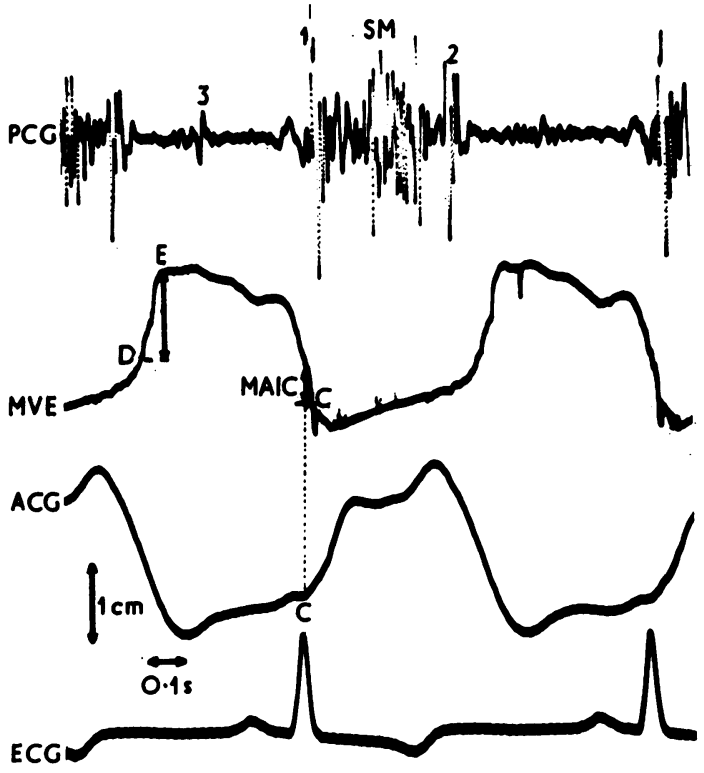

Fig. 5 Case 9 (Table 3). Hypertrophic obstructive cardiomyopathy. Reduced diastolic closure rate of mitral valve echogram but anterior mitral leaflet is near to closed position at $C$ point of apex cardiogram. MAIC $=4 \mathrm{~mm} . D E / M A I C$ ratio $=2.7$ (3=3rd heart sound, $S M=$ systolic murmur).

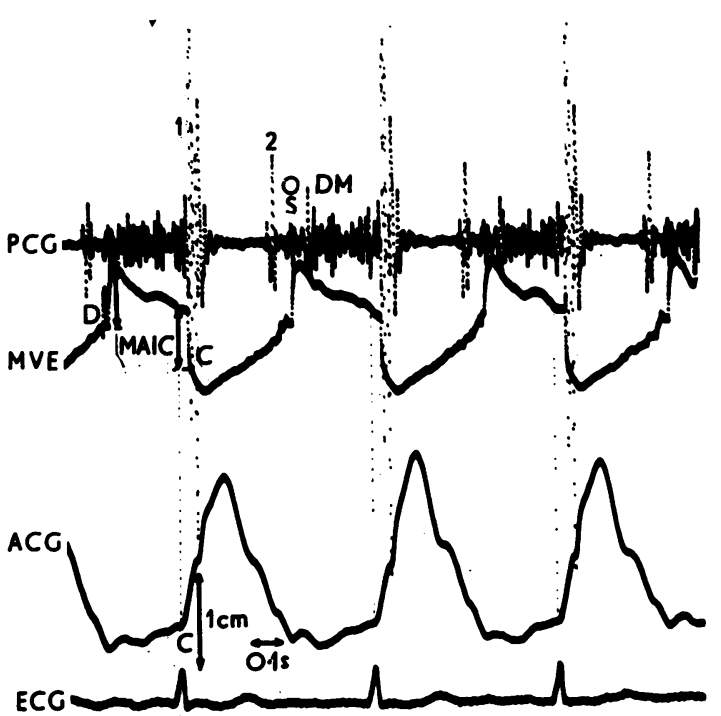

Fig. 6 Case 52 (Table 2). Mitral stenosis with very long diastolic murmur. Mitral valve area $1.0 \mathrm{~cm}^{2}$. Relatively slight decrease of diastolic closure rate (35 mm/s), but measurements of MAIC and DE/MAIC ratio more accurately reflect severity of mitral stenosis. $M A I C=6 \mathrm{~mm}, D E / M A I C$ ratio=1. (Note sharp contrast between this tracing and Fig. 4 and 5, in which though diastolic closure rate is lower valve is almost closed at $C$ point of $A C G$.) 
isovolumic contraction (MAIC) was easily measured. It was found that MAIC was always increased in patients with mitral stenosis, but fell within the normal range in those patients with aortic valvar stenosis or hypertrophic obstructive cardiomyopathy with a reduced diastolic closure rate of the anterior mitral valve leaflet.

The MAIC can be better assessed by the use of the DE/MAIC ratio, where DE measures the mitral echogram amplitude in early diastole. An excellent correlation was found between DE/MAIC ratio and mitral valve area in patients with mitral stenosis $(r=0.84, P<0.01)$, better than that between diastolic closure rate and mitral valve area $(r=0.62, P<0.01)$. These findings suggest that the DE/MAIC ratio could be useful in assessing the severity of mitral stenosis before or after mitral valvotomy; this is of practical value as it is now well recognised that the diastolic closure rate is an unreliable index of the severity of mitral stenosis (Cope et al., 1975).

In mitral stenosis there is a low filling rate of the left ventricle which is responsible for the reduced diastolic closure rate of the mitral valve echogram. We suggest that MAIC is a function of end-diastolic flow through the mitral valve. In normal subjects, anterograde mitral flow and MAIC are very small at end-diastole, when the anterior mitral leaflet is approaching the closed position (Laniado et al., 1975). In mitral stenosis the end-diastolic mitral flow depends primarily on the mitral valve area, but also on the duration of diastole, and is increased in severe mitral stenosis and at the end of a short diastole (Fig. 3); under these circumstances enddiastolic mitral gradient is increased, but it is persistence of flow which keeps the valve open. The poor correlation $(r=0.47)$ between end-diastolic gradient and DE/MAIC ratio suggests that this gradient is not directly responsible for the increase of MAIC in mitral stenosis. This conclusion is supported by our observation that MAIC is not influenced by the presence of left atrial contraction, which increases end-diastolic gradient; in atrial fibrillation the MAIC was increased to the same degree as in sinus rhythm. Finally, our view that MAIC in mitral stenosis is related to enddiastolic mitral flow is compatible with the observation that, in diseases other than mitral stenosis with mitral flow continuing through a significant part of diastole, diastolic closure rate is reduced (Feigenbaum and Chang, 1972; Laniado et al., 1975).

In the past, the concept that in mitral stenosis valve closure is delayed by an increased left atrial pressure led investigators (Wells, 1954; Kelly, 1955) to the familiar conclusion that $Q-S_{1}$ interval lengthens proportionally to the degree of mitral stenosis. However, the $\mathrm{Q}-\mathrm{S}_{\mathbf{1}}$ interval is not widely used in clinical practice: the mitral component of the first sound is not always distinct in the phonocardiogram, and the $\mathrm{Q}-\mathrm{S}_{1}$ interval is so short that even minor errors in its measurement do not allow accurate assessment of mitral stenosis. On the other hand, our findings show that mitral stenosis is easily assessed by the DE/MAIC ratio. In a mitral valve echogram with simultaneous electrocardiogram the onset of isovolumic contraction of the left ventricle ( $R$ wave of the electrocardiogram) and the end of mitral valve closure (C point on the echogram) are easily determined; moreover, the long distance between the points on the echogram corresponding to these two events minimises measurement errors.

In 10 of our patients with mitral stenosis the calculated mitral valve area was $1.20 \mathrm{~cm}^{2}$ and in another 3 it was $1.50 \mathrm{~cm}^{2}$. Even in these patients with less severe mitral stenosis the DE/MAIC ratio was less than normal. A low DE/MAIC ratio was also found in 9 patients in whom mitral stenosis was associated with mild mitral regurgitation. These findings suggest that the MAIC is greater than normal in patients with mild mitral stenosis and in patients with combined mitral stenosis and mild mitral regugitation.

Pridie and associates (1971) have shown premature closure of the mitral valve in aortic regurgitation and in 2 of 20 patients with combined aortic regurgitation and mitral stenosis. These observations suggest that the DE/MAIC ratio may not be a good index of the severity of mitral stenosis when aortic regurgitation is also present.

In the patients with aortic stenosis or hypertrophic obstructive cardiomyopathy the DE/MAIC ratio was within or close to the normal range, though in our selected patients with these diseases the diastolic closure rate on the echogram was reduced, probably as a result of reduced ventricular filling rate (Shah et al., 1969; Duchak et al., 1972). An incorrect diagnosis of mitral stenosis could be made, particularly in those patients with hypertrophic cardiomyopathy and a rumbling apical diastolic murmur (Shabetai and Davidson, 1972); in these cases the diagnosis of mitral stenosis is excluded by a normal DE/MAIC ratio.

In conclusion, DE/MAIC ratio is a sensitive index of the severity of mitral stenosis. Furthermore, by measuring this ratio, those cases can be identified in whom reduced diastolic closure rate on the mitral echogram is the result of reduced left ventricular compliance; in this way, the incorrect diagnosis of mitral stenosis can be avoided. 


\section{References}

Cope, G. D., Kisslo, J. A., Johnson, M. L., and Behar, V. S. (1975). A reassessment of the echocardiogram in mitral stenosis. Circulation, 52, 664.

Duchak, J. M., Jr., Chang, S., and Feigenbaum, H. (1972). The posterior mitral valve echo and the echocardiographic diagnosis of mitral stenosis. American fournal of Cardiology, 29, 628.

Feigenbaum, H., and Chang, S. (1972). Echocardiography, p. 70. Lea and Febiger, Philadelphia.

Fortuin, N., and Craige, E. (1973). Echocardiographic studies of genesis of mitral distolic murmurs. British Heart fournal, 35, 75.

Kelly, J. J., Jr. (1955). Diagnostic value of phonocardiography in mitral stenosis. American fournal of Medicine, 19, 862.

Laniado, S., Yellin, E., Kotler, M., Levy, L., Stadler, J., and Terdiman, R. (1975). A study of the dynamic relations between the mitral valve echogram and phasic mitral flow. Circulation, 51, 104.

Levisman, J. A., Abbasi, A. S., and Pearce, M. L. (1975). Posterior mitral leaflet motion in mitral stenosis. Circulation, $51,511$.

Pridie, R. B., Benham, R., and Oakley, C. M. (1971). Echocardiography of the mitral valve in aortic valve disease. British Heart fournal, 33, 296.

Shabetai, R., and Davidson, S. (1972). Asymmetrical hyper- trophic cardiomyopathy simulating mitral stenosis. Circulation, 45, 37

Shah, P. M., Gramiak, R., and Kramer, D. H. (1969). Ultrasound localization of left ventricular outflow obstruction in hypertrophic obstructive cardiomyopathy. Circulation, 40, 3.

Ticzon, A. R., Damato, A. N., Carata, A. R., Lau, S. H., and Gross, L. (1975). Echocardiographic manifestation of 'false' mitral stenosis that was. Annals of Internal Medicine, 83, 503.

Toutouzas, P., Kö dakis, A., Velimezis, A., and Avgoustakis, D. (1974). Mechanism of diastolic rumble and presystolic murmur in mitral stenosis. British Heart fournal, 36, 1096.

Wells, B. (1954). The assessment of mitral stenosis by phonocardiography. British Heart fournal, 16, 261.

Willems, J. L., De Geest, H., and Kesteloot, H. (1971). On the value of apex cardiography for timing intracardiac events. American fournal of Cardiology, 28, 59.

Zaky, A., Nasser, W. K., and Feigenbaum, H. (1968). Study of mitral valve action recorded by reflected ultrasound and its application in the diagnosis of mitral stenosis. Circulation, 37, 789 .

Requests for reprints to Dr. Pavlos Toutouzas, 10 Likiou Street, Athens (138), Greece. 